\title{
The effects of immunisation upon the natural history of pertussis. A family study in the Cardiff area
}

\author{
C. K. VESSELINOVA-JENKINS, 1 R. G. NEWCOMBE,2 O. P. GRAY,2 \\ J. F. SKONE, 1 C. H. L. HOWELLS, ${ }^{3}$ M. LENNOX, 1 D. J. HINE, \\ P. M. JENKINS, 1 AND J. A. MUNRO ${ }^{3}$
}

From the ${ }^{1}$ South Glamorgan Health Authority, the ${ }^{2}$ Welsh National School of Medicine, and ${ }^{3}$ the Public Health Laboratory Service, Cardiff

SUMMARY During an outbreak of pertussis in the Cardiff area in 1974, 229 children with the disease were studied to assess the effect of immunisation upon its natural history and severity. The typical clinical features of pertussis, such as paroxysmal cough, whooping, vomiting, cyanosis, and irregular breathing, were less prevalent in both the immunised and the older children. Immunisation is the main factor in protecting against complications such as fits; and, together with older age, it protects against hospitalisation. Nevertheless, pertussis today can be just as severe as it was $\mathbf{4 0}$ years ago, and the vaccine remains the major factor ameliorating its natural history. The immunisation programme needs more active support by all child health workers.

In 1974, public concern about the adverse complications of pertussis immunisation, with the consequent fall in the acceptance of immunisation, coincided with an outbreak of pertussis in the Cardiff area. This permitted a study of a considerable number of cases of the disease in both immunised and non-immunised children. This report is concerned with the effectiveness of the immunisation as measured by the severity of the disease in immunised and non-immunised children who contracted it.

\section{Patients and Methods}

The study population consisted of children up to the age of 16. They were either notified cases of pertussis, or affected contacts who had not been notified to the Medical Officer for Environmental Health (MOEH). A questionnaire was used to record details of the clinical manifestation of the disease. The original hospital notes of patients admitted to hopital were studied. Each child was visited three times or more. The immunisation history of each child was checked with records in the health authority offices and with general practitioners' records. A child was considered to have been fully vaccinated if a written record was found showing a completed primary course of three injections. Fourth and fifth injections, if given, were counted as boosters.
If the case was clinically identified before or during the fourth week from the beginning of the disease, a swab was taken from the surface of the nasopharynx and immediately cultured on BordetGengou media (Oxoid CM267). The plates wereso then sent to the public health laboratory for? bacteriological identification (Bradford et al., 1946). Virological investigation was not undertaken.

\section{Results}

The study consisted of 229 children in 145 families, diagnosed and treated for pertussis. Notifications to the MOEH provided 89 children $(39 \%)$. The remaining 140 children (61\%) were siblings, or other contacts, with pertussis, discovered as a result of visits to the families. Of the $\mathbf{2 2 9}$ children studied, $45 \%$ were boys, more than $80 \%$ were under six years old, and $44 \%$ were under two years old. Vaccination records showed that $116(51 \%)$ had not been vaccinated, $101(44 \%)$ were fully vaccinated, and $12(5 \%)$ were partially vaccinated. Nasopharyngeal swabs were obtained from $44(19 \%)$; one-quarter of these yielded Bordetella pertussis on culture. Ten of the 11 strains isolated were obtained from non-immunised children, and one was from a child who had had a single injection of pertussis vaccine.

The protective effect of vaccine against the severity of the disease was assessed by comparing 
vaccinated with unvaccinated children. Since no child aged under 18 months was completely vaccinated, a more adequate comparison was between the vaccinated and the unvaccinated children aged 18 months and older. The comparison between these older unvaccinated children and the necessarily incompletely protected children aged under 18 months provides an estimate of the effects of age upon the severity of the disease. Nevertheless, analysis of the children aged 18 months and older shows the unvaccinated to be substantially younger than the vaccinated (Table 1 and Fig. 1). We believe this to be a cohort effect, with acceptance of vaccine declining for successive cohorts. In Fig. 1, $53 \%$ of unvaccinated children aged eighteen months and older, but only $18 \%$ of the vaccinated, are under

Table 1 Mean age at diagnosis

\begin{tabular}{lrc}
\hline Group & No. & Age (months) \\
\hline Unvaccinated (aged under 18 months) & 80 & $6 \cdot 0$ \\
Unvaccinated (aged 18 months and older) & 36 & 51.0 \\
Adequately vaccinated & 100 & 65.9 \\
Inadequately vaccinated or unknown & 11 & $31 \cdot 3$ \\
Age not known & 1 & \\
$\quad$ Adequately vaccinated & 1 & \\
Inadequately vaccinated & 229 \\
Total & \\
\hline
\end{tabular}

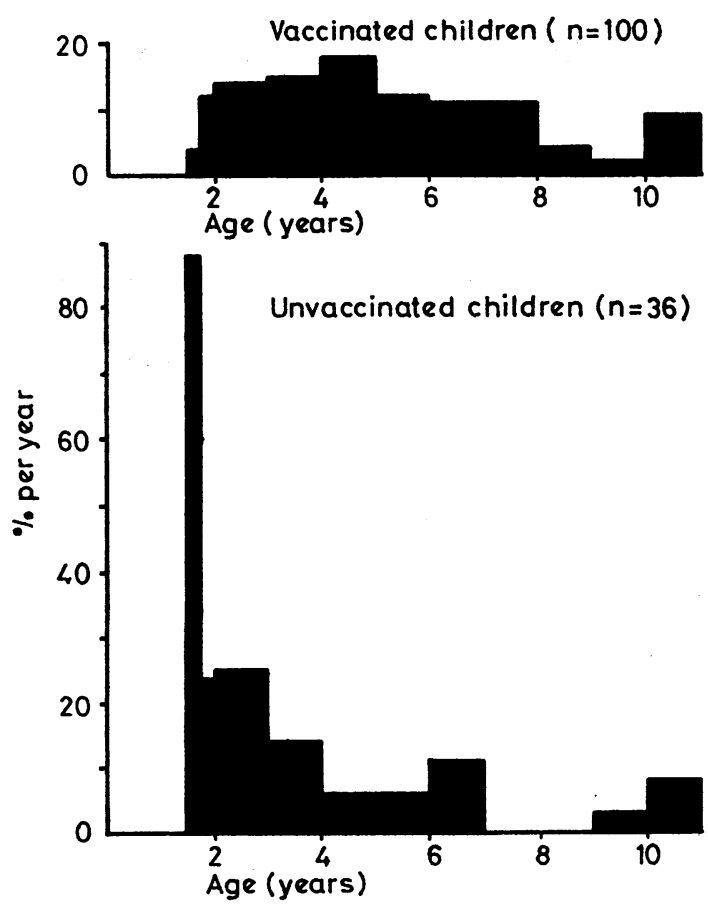

Fig. 1 Frequency distribution of age among vaccinated and unvaccinated children aged 18 months and older three years old, and according to the KolmogorovSmirnov test (Siegel, 1956) this difference of $35 \%$ is significant $(P<0.004)$. Thus we have not succeeded entirely in disentangling the effects of age and vaccination.

\section{Effects of age and previous immunisation on severity of pertussis}

Table 2 shows the prevalence of the various symptoms in vaccinated and unvaccinated cases, ignoring age. Details of symptoms were ascertained by visits to the family, interviews with parents and with family and community doctors, and from hospital notes. The presence, intensity, and frequency of the paroxysms of coughing accompanied by whoop, and also of vomiting, cyanosis, apnoeic attacks, convulsions, bronchopneumonia, and hospital admission were accepted as indices of the severity of the disease; statistically significant differences in the severity of pertussis can be seen between the vaccinated, inadequately vaccinated, and unvaccinated groups. In subsequent analysis, the unvaccinated children are divided into two groups-under 18 months of age and 18 months and older.

Table 2 Prevalence of clinical features of pertussis

\begin{tabular}{|c|c|c|c|c|}
\hline $\begin{array}{l}\text { Symptoms and } \\
\text { complications }\end{array}$ & $\begin{array}{l}\text { Adequately } \\
\text { vaccinated } \\
(n=101)\end{array}$ & $\begin{array}{l}\text { Inadequately } \\
\text { vaccinated } \\
(n=12)\end{array}$ & $\begin{array}{l}\text { Unvaccinated } \\
(n=116)\end{array}$ & $\begin{array}{l}\text { Total } \\
(n=229)\end{array}$ \\
\hline & $\%$ & $\%$ & $\%$ & $\%$ \\
\hline $\begin{array}{l}\text { Paroxysmal } \\
\text { cough }\end{array}$ & $99 \cdot 0$ & $100 \cdot 0$ & $99 \cdot 1$ & $99 \cdot 1$ \\
\hline $\begin{array}{l}\text { Facial } \\
\text { congestion } \\
\text { Whoop } \\
\text { Running nose }\end{array}$ & $\begin{array}{l}88 \cdot 1 \\
85 \cdot 1 \\
86 \cdot 1\end{array}$ & $\begin{array}{r}100 \cdot 0 \\
91 \cdot 7 \\
91 \cdot 7\end{array}$ & $\begin{array}{l}99 \cdot 1 \\
99 \cdot 1 \\
85 \cdot 4\end{array}$ & $\begin{array}{l}94 \cdot 3 \\
92 \cdot 6 \\
86 \cdot 0\end{array}$ \\
\hline $\begin{array}{l}\text { Sputum of } \\
\text { thick mucus } \\
\text { Temperature } \\
\text { Vomiting } \\
\text { Gasping }\end{array}$ & $\begin{array}{l}70 \cdot 3 \\
81 \cdot 2 \\
62 \cdot 4 \\
48 \cdot 5\end{array}$ & $\begin{array}{l}83 \cdot 3 \\
83 \cdot 3 \\
91 \cdot 7 \\
83 \cdot 3\end{array}$ & $\begin{array}{l}94 \cdot 8 \\
82 \cdot 8 \\
94 \cdot 8 \\
86 \cdot 2\end{array}$ & $\begin{array}{l}83 \cdot 4 \\
82 \cdot 1 \\
80 \cdot 4 \\
69 \cdot 4\end{array}$ \\
\hline $\begin{array}{l}\text { Pouring } \\
\text { saliva }\end{array}$ & $49 \cdot 5$ & $83 \cdot 3$ & $83 \cdot 6$ & $68 \cdot 6$ \\
\hline $\begin{array}{l}\text { Streaming } \\
\text { tears } \\
\text { Cyanosis } \\
\text { Bulging eyes } \\
\text { Fear and }\end{array}$ & $\begin{array}{l}49 \cdot 5 \\
37 \cdot 6 \\
31 \cdot 7\end{array}$ & $\begin{array}{l}75 \cdot 0 \\
83 \cdot 3 \\
75 \cdot 0\end{array}$ & $\begin{array}{l}81 \cdot 0 \\
81 \cdot 0 \\
78 \cdot 4\end{array}$ & $\begin{array}{l}66 \cdot 8 \\
62 \cdot 0 \\
57 \cdot 6\end{array}$ \\
\hline $\begin{array}{l}\text { anxiety } \\
\text { Dyspnoea } \\
\text { Pneumonia } \\
\text { Convulsions } \\
\text { Other symptoms }\end{array}$ & $\begin{array}{r}22 \cdot 8 \\
4 \cdot 0 \\
2 \cdot 0 \\
1 \cdot 0 \\
31 \cdot 0\end{array}$ & $\begin{array}{r}25 \cdot 0 \\
41 \cdot 7 \\
16 \cdot 7 \\
8 \cdot 3 \\
8 \cdot 3\end{array}$ & $\begin{array}{r}26 \cdot 7 \\
20 \cdot 0 \\
12 \cdot 9 \\
12 \cdot 1 \\
4 \cdot 3\end{array}$ & $\begin{array}{r}24 \cdot 9 \\
13 \cdot 5 \\
8 \cdot 3 \\
7 \cdot 0 \\
3 \cdot 1\end{array}$ \\
\hline
\end{tabular}

Table 3 shows considerable differences for some clinical symptoms between vaccinated and unvaccinated children. The lack of significant differences for the other symptoms may be merely the result of the small size of the older, unvaccinated group (36 children). Among children more than 18 months old, $94 \%$ of the unvaccinated vomited, but only $62 \%$ of the vaccinated $\left(\chi_{1}{ }^{2}=11 \cdot 70\right.$ 
Table 3 Prevalence of clinical features of pertussis: An attempt to separate the effects of age and vaccination

\begin{tabular}{|c|c|c|c|}
\hline $\begin{array}{l}\text { Symptoms and } \\
\text { complications }\end{array}$ & $\begin{array}{l}\text { Vaccinated } \\
\text { children } \\
(n=101) \\
\%\end{array}$ & $\begin{array}{l}\text { Unvaccinated } \\
\text { children } \\
18 \text { months } \\
\text { and older } \\
(n=36) \\
\%\end{array}$ & $\begin{array}{l}\text { Unvaccinated } \\
\text { children } \\
\text { Under } 18 \\
\text { months } \\
(n=80) \\
\%\end{array}$ \\
\hline \multirow[b]{2}{*}{$\begin{array}{l}\text { Whoop } \\
\text { Sputum of thick } \\
\text { mucus } \\
\text { Vomiting } \\
\text { Gasping } \\
\text { Cyanosis } \\
\text { Streaming tears } \\
\text { Pneumonia } \\
\text { Dyspnoea } \\
\text { Convulsions }\end{array}$} & $85 \cdot 1$ & $100 \cdot 0$ & $98 \cdot 7$ \\
\hline & $\begin{array}{r}70 \cdot 3 \\
62 \cdot 4 \\
48 \cdot 5 \\
37 \cdot 6 \\
49 \cdot 5 \\
2 \cdot 0 \\
4 \cdot 0 \\
1 \cdot 0\end{array}$ & $\begin{array}{r}94 \cdot 4 \\
94 \cdot 4 \\
83 \cdot 3 \\
72 \cdot 2 \\
83 \cdot 3 \\
0 \cdot 0 \\
27 \cdot 8 \\
11 \cdot 1\end{array}$ & $\begin{array}{l}95.0 \\
95.0 \\
87.5 \\
85.0 \\
80.0 \\
18.8 \\
15.0 \\
12.5\end{array}$ \\
\hline
\end{tabular}

$P<0.001$ ). Seventy-two per cent of older, unvaccinated children showed cyanosis during the cough paroxysms, compared with $38 \%$ in the vaccinated group $\left(\chi_{1}^{2}=11.41 \mathrm{P}<0.001\right)$. Whoops, gasping, streaming tears, bulging eyes, excessive secretion of saliva, and thick mucus were also less prevalent in the vaccinated group of children. The greater prevalence of each of these symptoms in unvaccinated compared with vaccinated children could not be explained away completely by the confusing effect of age. Dyspnoea is more common in the unvaccinated. $\left(\chi_{1}{ }^{2}=13.92 \quad P<0.001\right)$. Pneumonia is associated with age $\left(\chi^{2}{ }_{1}=6 \cdot 18\right.$ $P<0.02)$ but not with vaccination. In 16 children, fits and cyanosis developed at the end of a prolonged paroxysmal attack of coughing, followed by apnoea but no whoop. Boys and girls were equally affected. Two of the children had experienced fits in the past; one of them became worse during the illness, and for three months after the cough had ceased, he continued to have fits daily, in spite of intensive anticonvulsant therapy. Another two children, who had not been vaccinated against pertussis because of a family history of fits, developed fits for the first time during the illness. Fits are equally common in younger and older unvaccinated cases, but are less common in the vaccinated $(1 \%)$ than in the unvaccinated aged over 18 months $(11 \%) ;(2 \quad P=0.034$, Fisher's exact test) (Fisher, 1970). One unvaccinated child, with no previous fits, nor family history of fits, developed convulsions during pertussis and continued to have fits two or three times a month for six months without any connection with paroxysms of coughing. In addition to the two already mentioned, with a history of fits, there were eight others $(3.5 \%)$ not immunised, with a history of fits, but with no episode of fits during pertussis.

Treatment with antibiotics was given to no less than $96.5 \%$ of the total number of children under observation, and $98.3 \%$ were receiving various antitussive drugs. The duration of pertussis was also taken as an index of its severity. It is generally accepted (Bennett, 1973; Christie, 1974) that mild cases should improve before the end of the fourth week, so duration of more than a month was classified as severe pertussis (Fig. 2). The Kolmogorov-Smirnov test indicates that the effect of age on duration is not significant, but the effect of vaccine is statistically significant at the $2 \%$ level.

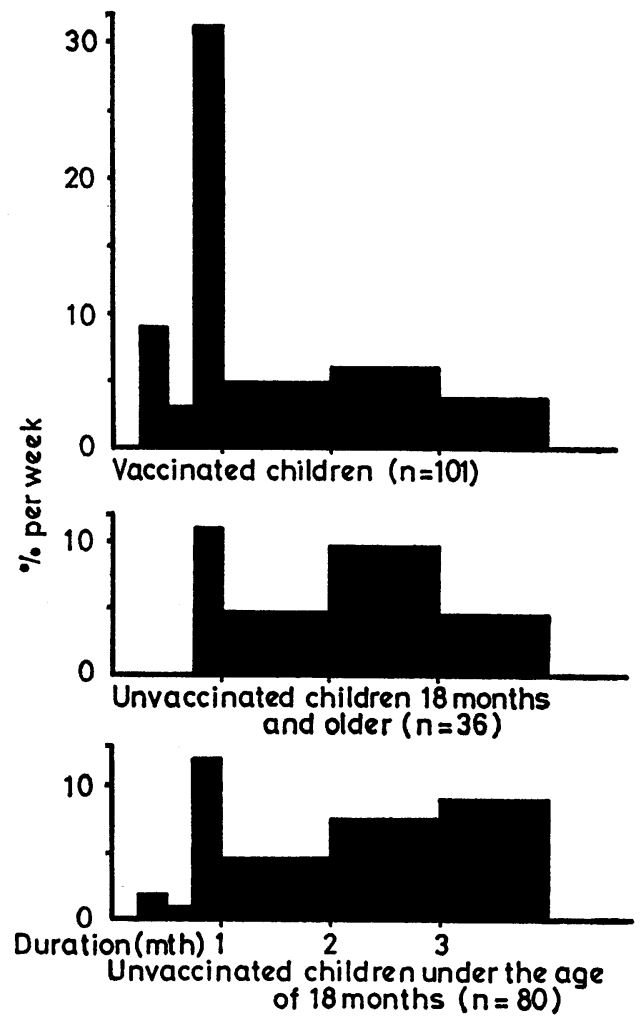

Fig. 2 Duration of pertussis among vaccinated and unvaccinated children.

The number of spasms of coughing in 24 hours varied from day to day as well as from patient to patient. In very mild cases, only a few paroxysmal attacks in 24 hours were recorded, while other attacks were described by parents as 'continuous' coughing. In all cases the condition of the children was worse at night.

The frequency of the paroxysms is presented in Fig. $3 ; 33 \%$ of vaccinated and $63 \%$ of unvaccinated cases had more than 30 spasms per day $(P<0.001)$. However, separation of the effects of age and vaccine makes it impossible to say whether age or vaccination accounts for the difference in frequency of paroxysms of coughing. In our study, admission to hospital was uncommon among the vaccinated, 

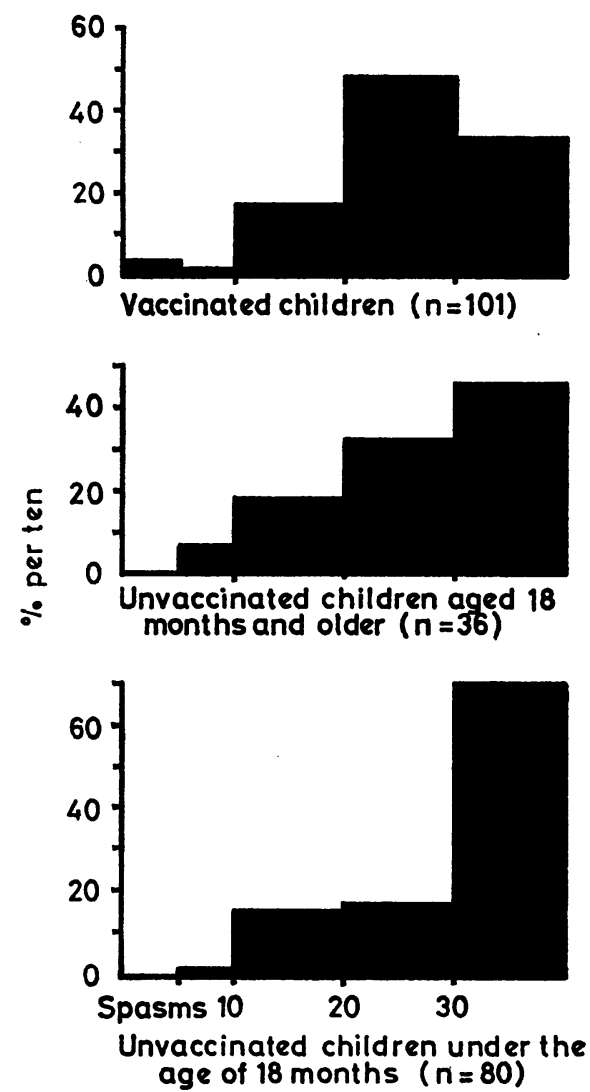

Fig. 3 Frequency distribution of number of spasms of coughing per 24 hours among vaccinated and unvaccinated children.

but age had an important effect. Twenty-two per cent of all the 229 patients were admitted to hospital: among the unvaccinated, $49 \%$ of those under 18 months old and $14 \%$ of those aged over 18 months. Among the vaccinated, however, only $3 \%$ were admitted to hospital. The effects of both age and vaccine $\left(\chi_{1}{ }^{2}=10.95\right.$ and 3.94$)$ are significant $(P<0.001$ and $P<0.05)$.

The sources of infection appear to be mainly siblings and school friends, but the 'source not known' groups are too large for meaningful tests of significance; as expected 'school friend' is less common among the unvaccinated, simply because they are younger. In $4 \%$ of cases the infection was judged to have been contracted from one of the parents.

\section{Discussion}

The study confirms the view that pertussis in young infants is a severe disease (Lapin, 1943; Bennett,
1973; Christie, 1974; Joint Committee on Vaccination, 1975; Miller and Fletcher, 1976; Joint Committee on Vaccination, 1977; Stewart, 1977a). We found that $49 \%$ of our patients aged under 18 months were considered sufficiently ill to be admitted to hospital. The main reason for admission was the severity of the disease, for example, frequent prolonged paroxysms of coughing, accompanied by vomiting, irregularity of breathing with sequences of apnoea, cyanosis, and development of pneumonia and fits. The period of paroxysmal coughing was longer, and vomiting, cyanosis, and irregular breathing were more common, in the nonimmunised group of children. Rapid recovery within one month was more common in the vaccinated group (43\%) than in the older non-vaccinated children $(11 \%)$. Fits were less common in the vaccinated $(1 \%)$ than in the non-vaccinated $(11 \%)$, and were equally common in younger and older non-vaccinated children. We have not observed any of the clinical cerebral complications, such as paralyses, blindness, loss of visual acuity, deafness, mental retardation, ataxia, speech disorders, and personality and behaviour problems as found by others (Litvak et al., 1948), but the frequency of convulsions we observed in all the non-vaccinated children $(12 \%)$ is very similar to the $8 \%$ observed in a hospital study in 1933-36 before the advent of mass vaccination (Hambel and Lucchesi, 1938). One must remember that a considerable time has to elapse before the development of any personality changes and behaviour disorders becomes apparent. Cyanosis from severe paroxysmal coughing, sometimes followed by apnoea, was recorded in $72 \%$ of the older unvaccinated children, and in $85 \%$ of the younger unvaccinated children, compared with the much lower incidence of cyanosis $(38 \%)$ in the group of immunised children. Attacks of cyanosis and asphyxia during pertussis have been held to be just as frequently responsible as asphyxia neonatorum for the development of a particular abnormal behaviour syndrome in children 'completely recovered' from severe pertussis in their early childhood (Rosenfeld and Bradley, 1948).

This study shows that, contrary to recent reports, pertussis is not always a benign disease (Barrie, 1977; Stewart 1977b). Even after allowing for the effect of age, pertussis immunisation is one of the factors ameliorating the severity of pertussis, and the main factor in protecting against the complication of fits. Although the proportion of immunised children with severe pertussis was considerably lower than that of the non-immunised, $24 \%$ of the fully immunised children experienced paroxysmal coughing for more than two months, and $15 \%$ continued to have paroxysms for more than 
three months. It has been claimed that pertussis vaccination has never been a success, and that immunity after vaccination is of short duration (Linnemann et al., 1974; Lancet, 1977; Stewart, 1977a). This could explain the cases of those who contracted the disease in spite of a completed primary course of three injections and a booster. On the other hand, it is difficult to rule out the possibility that some other respiratory infection may give rise to the whooping cough syndrome in the individual case.

It has been suggested (Blattner, 1964; Olsen, 1964; Collier, 1966; Pereira, 1971; Stewart, 1977b) that this syndrome can be caused by other known agents; and the bimodality of the distribution of duration of illness is consistent with a mixed aetiology. This possibility complicates the problem, and makes it difficult to form a comprehensive assessment of the effectiveness of pertussis vaccine. In this series, swabs could be obtained only from a small proportion of cases, normally during the fourth week of the illness. Thus, in the majority of cases studied, there could be no proof that Bordetella pertussis was the causative agent of the whooping cough syndrome. Nevertheless, children who had been protected by vaccine were far less likely to yield Bordetella pertussis on culture of pharyngeal swabs, and they had a far less severe illness; this suggests that this organism was responsible for the most severe cases of the whooping cough syndrome.

Similarly, in a study based on the whole of the United Kingdom (Public Health Laboratory Service Whooping Cough Committee and Working Party, 1973) it has been claimed that Bordetella pertussis remains the major identifiable cause of whooping cough. Thus, pertussis vaccine will be the only effective measure to prevent the whooping cough syndrome until we fully understand its pathogenesis (Vesselinova, 1964) and discover methods of treatment which are effective regardless of the aetiological agent.

\section{Conclusions}

The present situation regarding pertussis vaccine as a factor in preventing and modifying pertussis is quite different from that in 1974 because of the extremely low immunisation rate; this is attributable to the publicity about the side-effects of the vaccine (Madsen, 1933; Kulenkampff et al., 1974) which led to an extensive analysis and reassessment of the present facts on the morbidity, severity, complications, and deaths from pertussis (Joint Committee on Vaccination and Immunisation, 1977).
The results reported here, and the impressions formed in the Cardiff area during the outbreak of pertussis in 1974-75, may not necessarily apply to other parts of Britain. Nevertheless, this study supports the Joint Committee's recommendation of the continued use of pertussis vaccine for the protection of infants, and the view that the advantages of an earlier start to immunisation, at three months of age, outweigh the stronger immunological response found at six months of age.

We are grateful to the parents of the children in the study; the many doctors who cared for the children and undertook their laboratory tests; and to Mrs. L. Viggers, Mrs. W. Hockings, Mrs. S. Fullalove and Miss M. K. Bailey.

Reprints from C. K. Vesselinova-Jenkins, 24, Albany Road, Blackwood, Gwent NP2 1DZ, South Wales.

\section{References}

Barrie, H. (1977). Whooping cough vaccination. Lancet. $1,648$.

Bennett, N. McK. (1973). Whooping cough in Melbourne. Medical Journal of Australia, 2, 481-487.

Blattner, R. J. (1964). The whooping cough syndrome. Journal of Pediatrics, 65, 150-152.

Bradford, W. L., Day, E., and Berry, G. P. (1946). Improvement of the nasopharyngeal swab method of diagnosis in pertussis by the use of penicillin American Journal of Public Health, 36, 468-470.

Christie, A. B. (1974). In Infectious diseases: Epidemiology and clinical practice, p. 744. Churchill Livingstone: Edinburgh.

Collier, A. M., Connor, J. D., and Irving, W. R. (1966). Generalised type 5. Adenovirus infection associated with the pertussis syndrome. Journal of Pediatrics, 69, 1073-1078.

Fisher, R. A. (1970). Statistical methods for research workers. Oliver and Boyd: Edinburgh.

Hambel, K., and Lucchesi, P. F. (1938). Convulsions complicating pertussis. American Journal of Diseases of Children, 56, 275-286.

Joint Committee on Vaccination and Immunisation of the Central Health Services Council and the Scottish Health Service Planning Council (1975). Whooping cough vaccine. British Medical Journal, 3, 687-688.

Joint Committee on Vaccination and Immunisation (1977). Review of the Evidence on Whooping Cough Vaccination, pp. 18 and 34. HMSO: London.

Kulenkampff, M., Schwartzman, J. S., and Wilson, J. (1974). Neurological complications of pertussis inoculation. Archives of Disease in Childhood, 49, 46-49.

Lancet (1977). Editorial: Whooping cough vaccination. Lancet, 2, 71-72.

Lapin, J. H. (1943). Whooping cough, p. 112. Charles C. Thomas: Springfield. 
Linnemann, C. C., Jr., Partin, J. C., Perestein, P. H., and Englender, G. S. (1974). Pertussis: persistent problem. Journal of Pediatrics, 85, 589-591.

Litvak, A. M., Gibel, H., Rosenthal, S. E., and Rosenblatt, P. (1948). Cerebral complications in pertussis. Journal of Pediatrics, 32, 357-379.

Madsen, T. (1933). Vaccination against whooping cough. Journal of the American Medical Association, 101, 187-188.

Miller, C. L., and Fletcher, W. B. (1976). Severity of notified whooping cough. British Medical Journal, 1, 117-119.

Olsen, L. C., Miller, C., and Hanshaw, J. B. (1964). Acute infectious lymphocytosis presenting as a pertussis-like illness: its association with adenovirus type 12. Lancet, 1, 200-201.

Pereira, M. S., and Candeias, J. A. N. (1971). The association of viruses with clinical pertussis. Journal of Hygiene, 69, 399-403.
Public Health Laboratory Service Whooping Cough Committee and Working Party (1973). Final report to the Director of the Public Health Laboratory Service: Efficacy of Whooping Cough vaccines used in the United Kingdom before 1968. British Medical Jouraal, 1, 259-262.

Rosenfeld, G. B., and Bradley, C. (1948). Childhood behaviour sequelae of asphyxia in infancy, with special reference to pertussis and asphyxia neonatorum. Pediatrics, 2, 74-78.

Siegel, S. (1956). Nonparametric statistics for the behavioural sciences, pp. 127-136. McGraw-Hill: New York.

Stewart, G. T. (1977a). Vaccination against whooping cough. Efficacy versus risks. Lancet, 1, 234-237.

Stewart, G. T. (1977b). Whooping cough vaccine. Lancet, 2, 189-190.

Vesselinova, C. K. (1964). On the pathogenesis of pertussis and parapertussis. Savremenna Medicina (Sofia, Bulgaria), 12, 23-27. 